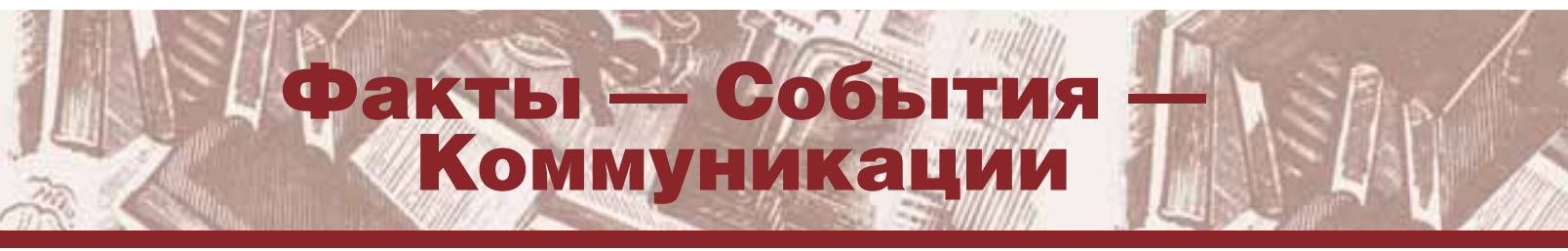

УДК 655.42(470-25)

ББК 76.184.712(2-2Москва)

DOI 10.25281/0869-608X-2019-68-5-553-559

Е.Н. ВОЛХОНСКАЯ, Е.В. НИКОНОРОВА

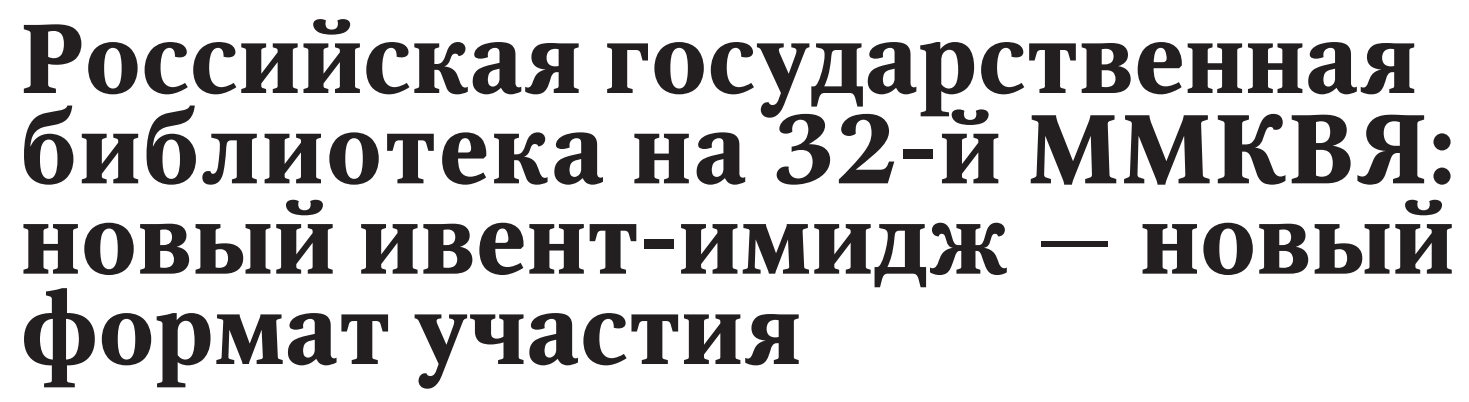

Реферат. 32-я Московская международная книжная выставка-ярмарка (ММКВЯ) проходила с 4 по 8 сентября 2019 г. Цель данной статьи - переосмыслить роль Российской государственной библиотеки (РГБ) в событийном и коммуникационном пространстве ММКВЯ: с одной стороны, как одного из субъектов книжного дела, хранителя ценностей культуры, а с другой - как крупнейшего библиотечного книгоиздателя. Концепция стенда РГБ как экспонента выставки-ярмарки разрабатывалась и была выстроена исходя из этого бинарного модуса Библиотеки, с акцентами на те элементы, которые отражают цепочку перехода от старопечатной к современной печатной книге, а от нее к новым цифровым форматам. На стенде были выделены зоны издательства РГБ «Пашков дом» и научно-исследовательского отдела редких книг (Музея книги), модуль сохранности и реставрации фондов, консультационно-разъяснительный правовой модуль, обеспечивающий коммуникации с издателями и авторами по вопросам Национальной электронной библиотеки (НЭБ) и обязательного экземпляра печатного издания в электронной форме. Содержательная программа работы стенда была соответственно разноплановой и насыщенной. Представлена новая продукция издательства «Пашков дом», презентованы проекты, подготовленные к выпуску в свет в сотрудничестве с партнерами и собственными силами. Проанализированы основные тезисы авторов, составителей и издателей, выступавших на стенде РГБ, а также тематика публичных лекций на открытых площадках. Раскрыты новые возможности НЭБ как одного из ведущих проектов РГБ, внутри которого сочетаются различные модели взаимоотношений издателей, авторов произведений и библиотек. Освещаются итоги конкурса Российской библиотечной ассоциации «Лучшая профессиональная книга года». Задан новый формат участия РГБ в выставках-ярмарках и подобных событиях. Этот формат, в свою очередь, формирует новый ивент-имидж РГБ, который позиционирует Библиотеку не только как институт памяти, хранящий величайшее культурное наследие книги, как центр интеллектуального развития и профессионального взаимодействия, но и как активного участника книгоиздательского процесса.

\author{
Елена Николаевна Волхонская, \\ Российская государственная библиотека, \\ отдел периодических изданий, \\ редактор \\ Воздвиженка ул., д. 3/5, \\ Москва, 119019, Россия \\ ORCID 0000-0003-2685-3696 \\ E-mail: VolkhonskayaEN@rsl.ru
}

Екатерина Васильевна Никонорова,

Российская государственная библиотека,

Департамент - Издательство «Пашков дом», директор,

отдел периодических изданий,

заведующая

Воздвиженка ул., д. 3/5,

Москва, 119019, Россия

доктор философских наук, профессор

ORCID 0000-0001-9482-1536; SPIN 7897-9542

E-mail: NikonorovaEV@rsl.ru 
Ключевые слова: Московская международная книжная выставка-ярмарка, ММКВЯ, Российская государственная библиотека, РГБ, Пашков дом, Российская библиотечная ассоциация, РБА, ивент-имидж, книга, библиотечные коллекции, книгоиздательство, научно-методическая литература, профессиональная литература, редкая книга, партнерство, национальная библиотека, национальный проект, Национальная электронная библиотека, НЭБ, обязательный экземпляр печатного издания, консервация и реставрация документов.

Для цитирования: Волхонская Е.Н., Никонорова Е.В. Российская государственная библиотека на 32-й ММКВЯ: новый ивент-имидж - новый формат участия // Библиотековедение. 2019. Т. 68, № 5. C. 553-559. DOI: 10.25281/0869-608X-2019-68-5-553-559.

M осковская международная книжная выставка-ярмарка (ММКВЯ) является одним из самых крупных мировых событий в области книгоиздания и книгораспространения. Это - важнейший культурный и социальный проект столицы. Книжный форум проходил с 4 по 8 сентября 2019 года. Место его проведения (Выставка достижений народного хозяйства, Москва) осталось традиционным, а команда организаторов и принципы работы изменились. «Перезагрузка» анонсировалась еще в июне 2019 г., во время книжного фестиваля «Красная площадь», когда издателей пригласили высказывать пожелания, многие из которых были учтены [1, с. 334]. Генеральный директор ММКВЯ А.В. Гельмиза отметил, что «в этом году на выставке было много небольших издательств и молодых проектов», ее участниками стали 33 страны, 29 городов России, состоялось 600 мероприятий. Почетный гость ММКВЯ - Республика Беларусь, специальный «город-гость» Шарджа (Объединенные Арабские Эмираты).

Российская государственная библиотека (РГБ) как национальная библиотека страны является институтом памяти, сохраняющим величайшее культурное наследие - книги, авторитетнейшим центром изучения и реставрации книжных и рукописных памятников. Но одновременно это - и значимая книгоиздающая структура, представленная издательством «Пашков дом». Концепция стенда РГБ как экспонента выставки-ярмарки разрабатывалась и была выстроена исходя из этого бинарного модуса Библиотеки, с акцентами на те элементы, которые отражают цепочку перехода от старопечатной к современной печатной книге, а от нее - к новым цифровым форматам. Были выделены зоны издательства «Пашков дом» и научно-исследовательского отдела (НИО) редких книг (Музея книги) РГБ, модуль сохранности и реставрации фондов, консульта- ционно-разъяснительный правовой модуль, обеспечивающий коммуникации с издателями и авторами по вопросам федеральной государственной информационной системы «Национальная электронная библиотека» (НЭБ) и обязательного экземпляра печатного издания в электронной форме.

РГБ представила вниманию посетителей насыщенную и разноплановую программу: каждый день на стенде проходили презентации наиболее значимых библиотечных проектов, коллекций и направлений деятельности, книгоиздательских новинок. Раскрывая свои богатейшие фонды, РГБ ежедневно демонстрировала раритеты из собрания Музея книги. Витрина, в которой экспонировались подлинники изданий, стала смысловым и концептуальным ядром выставочного пространства Библиотеки. Часть экспозиции ежедневно менялась, «иллюстрируя» темы презентаций книг издательства «Пашков дом», часть же была постоянной: к ней для наглядности обращались эксперты-реставраторы РГБ, в течение всей выставки-ярмарки консультировавшие посетителей по вопросам сохранения и восстановления документов в частных собраниях. На стенде работали специалисты отдела реставрации библиотечных фондов под руководством начальника Управления обеспечения сохранности фондов РГБ А.А. Сошнина. Консультацию для владельцев фотоархивов провела эксперт по реставрации фотографий Е.А. Калистратова; в выступлении специалиста по славянскому, западноевропейскому и восточному переплетам XI-XVIII вв. В.В. Демидовой речь шла о тонкостях реставрации переплета.

Сегодня в России в рамках национального проекта «Культура» ведется развитие НЭБ, которая должна стать единой информационной платформой доступа к книгам в электронном формате. Иными словами, НЭБ ориентирована 
на новую модель удобного чтения. Оператором системы является РГБ, усовершенствовавшая работу, связанную с этим проектом [1, с. 332].

Важным для всего библиотечного и издательского сообщества событием стало подписание 4 сентября 2019 г. генеральным директором РГБ В.В. Дудой и президентом холдинга «Эксмо-АСТ» О.Е. Новиковым соглашения о сотрудничестве. Первый совместный проект РГБ и издателей связан с развитием НЭБ и размещением изданий холдинга на ее платформе. B.В. Дуда подчеркнул, что основная идея развития НЭБ очень проста - все, что издается в России, должно быть доступно на определенных условиях онлайн, потому что не у всех есть возможность приехать в Ленинку, чтобы получить доступ к современным книгам. «Средний тираж в России - меньше пяти тысяч экземпляров, а библиотек - около 40 тысяч, этих тиражей явно не хватает, и мы хотим исправить эту несправедливость». Подписанное соглашение предусматривает «и офлайн-, и онлайнсотрудничество, продвижение современных интересных книг».

Детальнее познакомиться с пространством НЭБ, узнать о новых возможностях и моделях взаимодействия издателей, авторов и библиотек, позволяющих обеспечить как защиту правообладателей произведений, так и широкий доступ к современным знаниям и информации, можно было на стенде Библиотеки. Специалисты Департамента интеллектуальных прав и нормативно-правового обеспечения РГБ рассказывали о лицензионных договорах: способах использования и порядке передачи произведений, правах и обязанностях сторон, требованиях к формату, установленной терминологии.

По данным Российской книжной палаты, около 50 библиотек в России ведут издательскую деятельность, причем флагманами в выпуске справочной и методической литературы по библиотечному делу, книговедению и библиографии являются именно библиотечные издательства [2, с. 708-709]. Издательство РГБ «Пашков дом», подготовившее к выходу в свет более 500 книжных изданий, 21 год занимается выпуском профессиональной литературы. На стенде РГБ был презентован выпущенный издательством «Пашков дом» второй том «Каталога славяно-русских рукописных книг из собрания Е.Е. Егорова» [3]. Собрание купца-старообрядца Егорова является одной из ценнейших в мире частных коллекций руко- писных книг. В каталоге представлены редчайшие памятники, в числе которых болгарский список середины XIV в. «Пандектов» Никона Черногорца, лицевое Евангелие начала XVI в. из Псково-Печерского монастыря, лицевое Учительное Евангелие, датируемое серединой XVI века. Презентация каталога собрала большой круг авторитетных ученых, специалистов и заинтересованных слушателей.

РГБ традиционно принимает участие в ежегодном конкурсе библиотечной книгоиздательской продукции «Лучшая профессиональная книга года», подведение итогов которого проводится Российской библиотечной ассоциацией (РБА) в первый день выставки-ярмарки [4]. В 2019 г. конкурс проходил по четырем номинациям: «В помощь профессионалу»; «История края»; «Полиграфическое исполнение»; «Книги для слепых и слабовидящих». Президент РБА М.Д. Афанасьев отметил, что интерес к конкурсу повышается год от года, а число и профессиональное мастерство участников растут.

$\mathrm{B}$ номинации «B помощь профессионалу» участвовало 21 издание. Победила книга И.Б. Михновой и А.А. Пурника, представленная Российской государственной библиотекой для молодежи (РГБМ), - «Эффективная библиотека: как обустроить библиотеку и сделать ее нужной людям» [5]. Специальный диплом президента РБА в этой номинации получили библиографический указатель «Александр Исаевич Солженицын», подготовленный специалистами Российской национальной библиотеки [6], и монография «Сохранение исторической памяти об исчезнувших сельских поселениях: методология и методика создания и продвижения информационного ресурса» [7], предоставленная Тамбовской областной универсальной библиотекой им. А.С. Пушкина.

Номинация «История края» стала самой многочисленной: в ней участвовало 53 издания, а победителем стала Алтайская краевая универсальная научная библиотека им. В.Я. Шишкова [8].

За победу в номинации «Полиграфическое исполнение» соревновались восемь изданий, победила книга, представленная Камчатской краевой научной библиотекой и посвященная ее 190-летию [9]. В этой же номинации специального диплома президента РБА удостоился «Каталог переплетов Якоба Краузе и мастеров его круга. Ч. 2», подготовленный издательством РГБ «Пашков дом» в рамках серии «Коллекции 
Российской государственной библиотеки» [10]. Его автор, ведущий научный сотрудник НИО редких книг РГБ Т.А. Долгодрова отметила, представляя издание, что хранящаяся в Библиотеке коллекция (более 400 печатных книг и 8 манускриптов) является наиболее полным собранием самого прославленного немецкого переплетчика XVI века. Специальным дипломом жюри конкурса РБА «Лучшая профессиональная книга года - 2019» награждено издание Государственной публичной исторической библиотеки России: «Альтернативы Советской власти: листовки Гражданской войны из фондов ГПИБ России» [11].

В специальной номинации «Книги для слепых и слабовидящих» участвовало 9 изданий, победила книга, представленная Новосибирской областной специальной библиотекой для незрячих и слабовидящих «А.И. Покрышкин трижды Герой Советского Союза, маршал авиации» [12]. В этой же номинации специальный диплом президента РБА получила книга «Эдгар Дега: изобретатель социальной светотени» [13], представленная Санкт-Петербургской государственной библиотекой для слепых и слабовидящих.

Изучение, сохранение и собирательство книжных памятников лежит в основе библиотечной работы и библиофильского книгоиздания. На стенде РГБ состоялась презентация юбилейного номера (№ 50) журнала «Про книги», редакционный совет которого возглавляет председатель Национального союза библиофилов (НСБ), глава Федерального агентства по печати и массовым коммуникациям M.B. Сеславинский. Журнал выходит тиражом 500 экземпляров и продолжает традиции библиофильской периодики начала прошлого века, рассказывая о старинных книгах, изучении и собирательстве редких изданий. Номер представляли ответственный редактор С.С. Чистяков и исполнительный директор НСБ Б.А. Хайкин, вел презентацию заместитель генерального директора РГБ по научно-издательской деятельности А.Ю. Самарин.

Раскрытие фондов - основная задача библиотечного книгоиздания. Выпуск в свет издательством «Пашков дом» каждого тома «Сводного каталога русской книги. $1801-1825$ » становится событием для читателей - профессионалов и книголюбов. РГБ презентовала четвертый том [14] этого фундаментального издания, являющегося совместным проектом РГБ и крупнейших библиотек Москвы и Санкт-
Петербурга: Российской национальной библиотеки, Библиотеки Российской Академии наук, Государственной публичной исторической библиотеки России, Научной библиотеки Московского государственного университета им. М.В. Ломоносова, Научной библиотеки Санкт-Петербургского государственного университета, Научной библиотеки Российского государственного архива древних актов. Книгу представил коллектив авторов из НИО редких книг РГБ под руководством его заведующей Д.Н. Рамазановой.

На стенде Библиотеки состоялась презентация совместных проектов РГБ и издательства «СНЕГ» (Пятигорск). На страницах журнала «Библиотековедение» не раз шла речь об издательстве «СНЕГ», в сотрудничестве с которым издательством «Пашков дом» подготовлены замечательные издания: двухтомник «Книги, изменившие мир»; «Азбуки Ивана Фёдорова, его учеников и последователей» выдающегося ученого-книговеда Е.Л. Немировского; «Фауст» И.В. Гёте; «Приключения барона Мюнхгаузена» Р. Распэ; «Русские сказки и былины». Их отличает особый подход к каждой книге как к авторскому произведению искусства, в том числе и полиграфического.

Впервые вышел в свет весь комплекс черновиков романа М.А. Булгакова «Мастер и Маргарита», хранящихся в отделе рукописей РГБ. Его составитель Е.Ю. Колышева представила вниманию аудитории итог десятилетней работы в фондах РГБ: второе издание полного собрания черновиков романа в двух томах [15]. Исследовательница на основе сравнительного текстологического анализа и историко-биографических изысканий восстановила булгаковский текст, максимально отражавший замысел автора.

Одной из основных тем 32-й ММКВЯ была провозглашена детская литература. Иллюстрированная детская книга - особое направление книгоиздания, которое складывалось в нашей стране с конца XIX в. и связано с именами блестящих мастеров иллюстрации. Заведующая сектором формирования и научной обработки фондов НИО редких книг РГБ И.Л. Карпова рассказала о детской иллюстрированной книге из уникальной коллекции РГБ «Отечественные издания XIX - XX вв.», собиравшейся великолепными специалистами Д.Н. Чаушанским, А.А. Теремецкой, С.С. Ишковой.

Помимо консультаций на своем стенде, профессионалы РГБ приняли участие в меро- 
приятиях на общих площадках и коммуникационных пространствах выставки-ярмарки. Заведующая сектором музейной и выставочной работы НИО редких книг РГБ М.Б. Золотова выступила с публичной лекцией «Структура и элементы книги». Раскрыв структуру формы традиционной книги-кодекса, она рассказала о появлении и развитии основных ее элементов: титульного листа, иллюстрации, шрифта, переплета, их назначении, информационной роли, особенностях технологических и художественных решений.

Заместитель начальника отдела реставрации библиотечных фондов РГБ А.А. Новиков выступил с публичной лекцией «Сберечь нельзя испортить?», в которой познакомил слушателей с базовыми подходами к сохранению книг, принципами организации хранения книжного собрания в современных условиях. Речь шла о ключевых для любого книгохранилища характеристиках: климатических (влажность, температура), конструктивных (полки, раскладка), освещенности; о том, как предотвратить заражение и что делать с уже зараженным документом. А.А. Новиков заметил, что проблемы, с которыми имеют дело реставраторы в РГБ, являются общими как для частных книжных собраний, так и для крупных национальных библиотек всего мира.

РГБ - жемчужина культурного наследия, но, «сохраняя вечное», она участвует в современных, значимых для книжной отрасли страны событиях, в том числе и международного уровня, помогает авторам, издателям и читателям разбираться в новых форматах книги, знакомит их с новыми проектами и ресурсами. Оберегая традиции, Библиотека устремлена в будущее. Раскрывая свой духовный потенциал, она направляет его на развитие книжной культуры и чтения. Таким образом задается новый формат участия РГБ в выставках-ярмарках и подобных событиях, формирующий новый ивент-имидж Библиотеки.

\section{Список источников}

1. Волхонская E.Н. Библиотека и книга в эпоху цифровых технологий: векторы проектного развития // Библиотековедение. 2019. Т. 68, № 3. C. $330-335$. DOI: $10.25281 / 0869-608 X-2019-68-$ 3-330-335.

2. Волхонская Е.Н. Обсуждение издательской деятельности библиотек на non/fictio№ 20 // Биб- лиотековедение. 2018. Т. 67, № 6. С. 707-714. DOI: 10.25281/0869-608X-2018-67-6-707-714.

3. Анисимова Т.В. Каталог славяно-русских рукописных книг из собрания Е.Е. Егорова = Catalogue of slavic-russian manuscripts from the collection of E.E. Egorov. T. 2. Москва : Пашков дом, 2019.

4. Поздравляем победителей VII Конкурса РБА «Лучшая профессиональная книга года - 2019»! [Электронный ресурс] // Российская библиотечная ассоциация : офиц. сайт. URL: http://www. rba.ru/news/news_2442.html (дата обращения: 07.10.2019).

5. Михнова И.Б., Пурник А.А. Эффективная библиотека: как обустроить библиотеку и сделать ее нужной людям : практ. руководство. Москва, 2018. 432 c.

6. Александр Исаевич Солженицын : материалы к библиографии, 1962-2017: в 2 т. / [сост.: Д.Б. Азиатцев, Е.Н. Савельева, ред.: Т.В. Котова, Е.П. Семенова]. Санкт-Петербург : Дмитрий Буланин, 2018. 1696 с.

7. Сохранение исторической памяти об исчезнувших сельских поселениях: методология и методика создания и продвижения информационного ресурса : монография / Л.А. Пронина, В.В. Канищев, О.А. Суслова и др. ; под ред. Л.А. Прониной. Тамбов, 2018. 124 с.

8. В.М. Шукшин : биобиблиогр. указ. / Управление Алтайского края по культуре и арх. делу, Алтайская краевая универская науч. б-ка им. В.Я. Шишкова. Барнаул, 2018. 640 с.

9. Курохтина Н.И. Камчатская краевая научная библиотека: 190 лет развития. 1828-2018: исторический очерк / Камчатская краевая науч. б-ка им. С.П. Крашенинникова, Информ.-библиогр. отд. Петропавловск-Камчатский : Новая книга, 2019. 248 c.

10. Долгодрова Т.А. Каталог переплетов Якоба Краузе и мастеров его круга. Ч. 2.= Catalogue of bindings by Jacob Krause and masters of his circle. P. 2 / сост., авт. описания пер., книг и вступ. ст. Т.А. Долгодрова. Москва : Пашков дом, 2019. 512 с.

11. Альтернативы Советской власти: листовки Гражданской войны из фондов ГПИБ России : каталог выставки / сост.: А.Ю. Морозова, И.Ю. Новиченко, Е.Н. Струкова. Москва: ГПИБ России, 2018. 136 с.

12. А.И. Покрышкин - трижды Герой Советского Союза, маршал авиации : многоформат. пособие в рельеф.-точеч., рельеф.-графич., крупношрифтовом форматах / Новосибирская областная специальная библиотека для незрячих и слабовидящих. 2-е изд., испр. и доп. Новосибирск : [б. и.], 2018.

13. Эдгар Дега: изобретатель социальной светотени : многоформат. издание / В.В. Сперанская, 
В.В. Гуляева. Санкт-Петербург, 2019. 45 бр. л., 7 рел. ил., 50 с; ил., СD.

14. Сводный каталог русской книги. 1801-1825. Т. 4: П-Р / сост.: Л.Ю. Белова [и др.]. Москва : Пашков дом, 2019. 414 с.
15. Булгаков М.А. Мастер и Маргарита : полное собрание черновиков романа. Основной текст : в 2 т. / [сост., текстолог. подгот., публикатор, авт. предисловия, комментариев Е.Ю. Колышева]. 2-е изд. Москва : Пашков дом, 2019.

\title{
The Russian State Library at the 32nd Moscow International Book Fair: New Event-Image New Format of Participation
}

\author{
Elena N. Volkhonskaya ${ }^{\mathrm{a} *}$, Ekaterina V. Nikonorova ${ }^{\mathrm{b} * *}$, \\ Russian State Library, 3/5 Vozdvizhenka Str., Moscow, 119019, Russia \\ a ORCID 0000-0003-2685-3696 \\ b ORCID 0000-0001-9482-1536; SPIN 7897-9542 \\ E-mail: *VolkhonskayaEN@rsl.ru, **NikonorovaEV@rsl.ru
}

\begin{abstract}
The 32nd Moscow International Book Fair (MIBF) was held on 4-8 September 2019. The purpose of this article is to rethink the role of the Russian State Library (RSL) in the MIBF event and communication space: on the one hand, as one of the subjects of bookwork and preserver of cultural values, and on the other hand - as the largest library publisher. The concept of the RSL stand as the exhibitor at the exhibition-fair was developed and built on the basis of this binary mode of the Library, with emphasis on those elements that reflect the chain of transition from the early printed book to the modern printed book, and from it - to the new digital formats. The RSL stand contained the dedicated areas of the "Pashkov Dom" Publishing house and the Scientific research Department of rare books (Book Museum), the Module of preservation and restoration of collections, the Advisory-expository legal module providing communications with publishers and authors on the issues of the National Electronic Library (NEL) and legal deposit copy of the printed publications in electronic form. The content program of stand work was correspondingly diverse and rich. It presented new products of the "Pashkov Dom" Publishing house, new projects prepared for publication independently and in cooperation with partners. The article considers the main theses of the authors, compilers and publishers, who made presentations at the RSL stand, as well as the topics of public lectures in open areas. The author reveals the new perspectives of NEL as one of the leading projects of the RSL, which combines different models of relationship between publishers, authors and libraries. The article highlights the results of the library competition of the Russian Library Association (RLA) "Best Professional Book of the Year". The new format of participation of the RSL in exhibitions, fairs and similar events has been set. This format, in turn, forms a new event-image of the RSL, which positions the Library not only as an Institute of memory, which preserves the greatest cultural heritage - books, as a centre of intellectual development and professional interaction, but also as an active participant in the book publishing process.
\end{abstract}

Key words: Moscow International Book Fair, MIBF, Russian State Library, RSL, Pashkov Dom, Russian Library Association, RLA, event-image, book, library collections, publishing, scientific-methodical literature, professional literature, rare book, partnership, national library, national project, National Electronic Library, NEL, legal deposit copy of printed publication, preservation and restoration of documents.

Citation: Volkhonskaya E.N., Nikonorova E.V. The Russian State Library at the 32nd Moscow International Book Fair: New Event-Image - New Format of Participation, Bibliotekovedenie [Library and Information Science], 2019, vol. 68, no. 5, pp. 553-559. DOI: 10.25281/0869-608X-2019-68-5-553-559. 


\section{References}

1. Volkhonskaya E.N. Library and Book in the Digital Age: Project Development Vectors, Bibliotekovedenie [Library and Information Science (Russia)], 2019, vol. 68, no. 3, pp. 330-335 (in Russ.). DOI: 10.25281/0869-608X-2019-68-3-330-335.

2. Volkhonskaya E.N. Discussion of Publishing Activities of Libraries at Non/fictioNo 20, Bibliotekovedenie [Library and Information Science (Russia)], 2018, vol. 67, no. 6, pp. 707-714 (in Russ.). DOI: 10.25281/0869-608X-2018-67-6-707-714.

3. Anisimova T.V. Katalog slavyano-russkikh rukopisnykh knigiz sobraniya E.E. Egorova [Catalogue of Slavic-Russian Manuscripts from the Collection of E.E. Egorov], vol. 2. Moscow, Pashkov Dom Publ., 2019.

4. Congratulations to the Winners of the 7th Contest "Best Professional Book of the Year - 2019" by the Russian Library Association! Rossiiskaya bibliotechnaya assotsiatsiya: ofits. sait [Russian Library Association: official website]. Available at: http://www.rba.ru/news/ news_2442.html (accessed 07.10.2019) (in Russ.).

5. Mikhnova I.B., Purnik A.A. Effektivnaya biblioteka: kak obustroit' biblioteku i sdelat' ee nuzhnoi lyudyam: prakt. rukovodstvo [Effective Library: How to Develop a Library and Make It Useful to People: practical guide]. Moscow, 2018, $432 \mathrm{p}$.

6. Aleksandr Isaevich Solzhenitsyn: materialy k bibliografii, 1962-2017: $v 2 t$. [Aleksandr Isayevich Solzhenitsyn: Materials for Bibliography, 1962-2017: in 2 volumes]. St. Petersburg, Dmitrii Bulanin Publ., 2018, 1696 p.

7. Pronina L.A. (ed.) Sokhranenie istoricheskoi pamyati ob ischeznuvshikhsel'skikh poseleniyakh:metodologiya imetodika sozdaniya i prodvizheniya informatsionnogo resursa: monografiya [Preservation of the Historical Memory of Disappeared Rural Settlements: Methodology and Methods of Creation and Promotion of the Information Resource: monograph]. Tambov, 2018, 124 p.
8. V.M. Shukshin: biobibliogr. ukaz. [V.M. Shukshin: biobibliographic index]. Barnaul, 2018, 640 p.

9. Kurokhtina N.I. Kamchatskaya kraevaya nauchnaya biblioteka: 190 let razvitiya. 1828-2018: istoricheskii ocherk [Kamchatka Regional Scientific Library: 190 Years of Development. 1828-2018: historical essay]. Petropavlovsk-Kamchatsky, Novaya Kniga Publ., 2019, 248 p.

10. Dolgodrova T.A. Katalog perepletov Yakoba Krauze i masterov ego kruga. Ch. 2 [Catalogue of Bindings by Jacob Krause and Masters of his Circle. Part 2]. Moscow, Pashkov Dom Publ., 2019, 512 p.

11. Morozova A.Yu., Novichenko I.Yu., Strukova E.N. (eds). Al'ternativy Sovetskoi vlasti: listovki Grazhdanskoi voiny iz fondov GPIB Rossii: katalog vystavki [Alternatives to the Soviets: Civil War Leaflets from the State Historical Public Library of Russia: exhibition catalogue]. Moscow, GPIB Rossii Publ., 2018, $136 \mathrm{p}$.

12. A.I. Pokryshkin - trizhdy Geroi Sovetskogo Soyuza, marshal aviatsii [A.I. Pokryshkin - A Triple Hero of the Soviet Union, Air Marshal: multi-format]. Novosibirsk, 2018.

13. Edgar Dega: izobretatel' sotsial'noi svetoteni [Edgar Degas: The Inventor of Social Chiaroscuro: multiformat publication]. St. Petersburg, 2019. 45 br. p., 7 rel. il., 50 p., il., CD.

14. Belova L.Yu. (ed.) Svodnyi katalog russkoi knigi. 1801-1825. T. 4: $P-R$ [Union Catalogue of Russian Books. 1801-1825. Volume 4: P-R]. Moscow, Pashkov Dom Publ., 2019, 414 p.

15. Bulgakov M.A. Master i Margarita: polnoe sobranie chernovikov romana. Osnovnoi tekst: $v 2 t$. [The Master and Margarita: Complete Drafts of the Novel. Basic Text: in 2 volumes]. Moscow, Pashkov Dom Publ., 2019. 